\title{
THE ULCERATED MEATUS IN THE CIRCUMCISED CHILD *
}

\author{
JOSEPH BRENNEMANN, M.D. \\ CHICAGO
}

For a number of years my attention has been drawn with increasing frequency to a peculiar lesion of the meatus urinarius occurring only in circumcised male children, and characterized by ulceration, crusting, narrowing of the urinary passage, and nearly always accompanied by painful urination, often with distended bladder, and, occasionally, by hemorrhages. I have been able to find only one reference ${ }^{1}$ to it in the literature. While this condition probably is common in occurrence in the experience of all pediatrists, I am inclined to believe that it is more common in this locality and in more recent years than in some other localities and in my own earlier years, and that the manifestations are more severe.

My first impression was that this lesion was caused by rubbing against the clothing of the naturally most accessible and most vulnerable portion of the exposed glans, the meatus. This, however, seemed improbable, for it would hardly explain the deep ulceration often seen, and it was soon evident that similar lesions about the diaper region were not infrequently present at the same time. For a time attention was directed to the narrowness of the meatus as a possible cause, though we soon learned that in doing so we were looking for a cause in what was in reality an effect. Routine examination of the urine gave us no help. Only in the last year or two has the real explanation become increasingly evident. In the twenty-five or more cases seen during the past winter and spring there has been no exception to the observation that this lesion is associated with what is known as the ammoniacal diaper. I had not been aware that anyone had ever reached a similar conclusion, but on looking over Zahorsky's paper $^{1}$ on the ammoniacal diaper again I found that he had devoted a paragraph to an excellent description of the lesion in question and had also traced its origin to the ammoniacal diaper. So far as I know this is the only reference to this association in the literature.

While the condition itself is rarely, if ever, of serious import, it is nevertheless usually very troublesome and the apparent general lack of knowledge of its pathogenesis would seem to warrant its presenta-

\footnotetext{
* Received for publication, July 1, 1920.

* Read at the annual meeting of the American Pediatric Society, May 30 and 31 , June $1,1920$.

1. Zahorsky, J.: The Ammoniacal Diaper in Infants and Young Children, Am. J. Dis. Child. 10:475 (Dec.) 1915.
} 
tion. Its peculiar location, moreover, always causes deep concern in the household.

More commonly the lesion manifests itself as a rather superficial ulceration about the meatus. From what we know about the development of similar ulcers in the diaper region due to the same cause it is probably preceded, as pointed out by Zahorsky, ${ }^{1}$ by a vesicle, though this is rarely seen before it is broken. At times the ulcer becomes deep and extensive, up to $2 \mathrm{~mm}$. in depth and more than $5 \mathrm{~mm}$. in width. Usually it is more or less covered by a crust which is very firmly attached over a considerable area. Surrounding the ulcer there is often an area of inflammation which involves both the adjacent surface of the glans and extends into the urethral opening with consequent narrowing. In the severer cases there are commonly present at the same time erythema, vesication and ulceration of the glans, scrotum and the rest of the diaper region wherever the diaper is in intimate contact with the skin.

\section{SYMPTOMS}

The symptomatology is evident from the pathology. The salty urine coming in contact with the denuded meatus causes acute pain when the child begins to urinate. He immediately stops urinating and cries with pain. A subsequent attempt to urinate, as the discomfort from a distended bladder forces him to try it again, leads to the same result. No amount of coaxing will induce him to try it again until the distended bladder becomes intolerable or begins to overflow. Then, having once started, the grateful relief that comes from emptying the bladder and the lessening of the pain of the first contact with the urine, will cause him to continue to urinate until the bladder is more or less emptied. Unless the condition is quickly remedied the same cycle repeats itself at the next urination. Often the emptying of the bladder is deferred for from twelve to eighteen hours. As a rule, the condition is less severe than that just described, and the child will urinate before there is very painful distention.

In some cases there is a greater or lesser degree of mechanical obstruction. The urethral opening is nearly always narrowed, often so much so that the urinary stream is threadlike and the urine can be expelled only with evident effort. I have never seen this alone cause serious obstruction. A more frequent cause of nearly complete obstruction is the scab that forms on the ulcerated area. This is very adherent and can hardly be removed without tearing and bleeding of the denuded and adjacent portion of the glans. This is practically always accompanied by a narrowing of the meatus, and it is at times impossible to tell whether the occlusion is due chiefly to the scab or to the narrowing of the urethra itself. Two cases that recently came under observation illustrate these points. 


\section{REPORT OF CASES}

CASE 1.-A child, aged 2 years, was unable to empty the bladder both because of pain and obstruction and because of overdistention of the bladder. From time to time, there was a dribbling overflow that found considerable difficulty in making its exit. In spite of desperate efforts, aided by coaxing from his mother, he was able only intermittently to force out to a height of two feet two tiny divergent streams no thicker than a fine thread.

Examination showed the meatus completely covered with a firm, dry, parchment-like crust that almost completely occluded the opening, and so firmly adherent that it did not seem expedient to remove it at the time. The bladder was distended almost to the umbilicus. By continuous, gentle pressure over the bladder, and with much coaxing to voluntary effort, we were finally able to empty it almost completely through the two minute openings. If pressure over the bladder was stopped for a moment, the flow would stop immediately as if the bladder had been paralyzed by the overdistention.

CASE 2.-A boy, aged $2 \frac{1}{2}$ years, was apparently unable to empty the bladder, probably both because of pain and of great narrowing of the meatus. The opening was barely visible, being so small that it would hardly have admitted a fine needle. The meatus itself was apparently narrowed to this degree and was further covered by a tough skinlike crust that had to be removed, but only at the expense of considerable pain and some blood and adjacent epidermis. Even then the meatus could barely be made out, and it was difficult to see how the bladder could be emptied through it.

A permanent narrowing of the meatus, analogous to a stricture, apparently never occurs even after repeated and prolonged ulceration. In the two cases just cited, after appropriate treatment, the urinary stream was apparently of normal caliber on the following day. The restoration to a normal condition is commonly as rapid as the original production of the lesion itself.

One other symptom occasionally causes great concern to the mother but is never serious. If the ulceration is deep and extensive, there is, at times, a little hemorrhage especially noticed at the end of urination. It is surprising that this does not happen oftener when one considers the great vascularity of the glans.

The ammoniacal diaper that apparently always causes this condition of the meatus is to me still surrounded with mystery in spite of its common occurrence. Clinically it manifests itself as follows. An infant or young child that has, perhaps, attracted no attention to its general health or its state of nutrition, or digestion, except that it is constipated, is noticed when changed at night or in the morning, to have a very strong odor of ammonia about the wet diaper. This odor is not simply one detectable on close effort. The fumes are comparable to those that escape from a bottle of ammonia. They are distinctly irritating to the nostrils, and even cause a biting sensation in the eyes as one stoops over the open diaper. This condition is rarely noticed, except at night and most often toward morning. If the urine of such a child voided later is allowed to stand in a vessel no odor of ammonia is detectable even if it is kept at body temperature. 
Sometimes, the condition is present every night, continuously and consecutively, as in a case I saw recently, for over a year. Again, it is apparently absent, or barely noticeable, for weeks and months, only to appear again without any known change in health or in food, with violent manifestations. In one of my own children during the second year the condition would occasionally appear in mild form, then be absent for weeks or months. Suddenly at night, without premonition, or any known provocation, the child would wake up toward morning screaming with pain, the diaper would be almost intolerably strong of ammonia, and the whole diaper region would be reddened and painful as if scalded, and covered with blisters. In a day or so without any treatment the condition would disappear as mysteriously as it came, only to reappear at a subsequent time, perhaps for a longer stay. The condition is apparently much more frequent in private homes than in hospital wards.

Many children have this ammoniacal diaper for weeks and months without any other unpleasant symptoms. Usually it produces at least a local redness and subsequent desquamation of a large part of the diaper region. In severer cases there is scattered vesication and ulceration. These ulcers often remain denuded for a long time, often they heal over but remain as discrete nodules during the whole time that the ammoniacal condition persists. Often the exposed meatus is the only seat of a deeper lesion; rarely it escapes; as a rule, it is involved with the rest of the diaper region.

For the production of skin lesions contact with the wet ammoniacal diaper is apparently always necessary. The word diaper is, of course, here used in a generic sense and includes any article of clothing, or bedding. The skin is always most irritated where the contact is most intimate and prolonged - over the buttocks and lower back, from lying, and across the abdomen and about the thighs above the knees, because of the tighter application of the diaper. The male meatus is peculiarly exposed to such contact, and the delicate mucous membrane is the most vulnerable spot; the female meatus is well protected and is apparently rarely if ever involved. The effect of contact was well illustrated in the first case cited above. For several nights the child did not wet the diaper and the ulcer healed. A few days later he was again unable to urinate because of a new ulceration of the meatus. Without any questioning the mother said that he had wet his underclothing over a small spot with urine and that contact with this spot had apparently brought the trouble on again. The favorable effect that follows dispensing with the diaper at night further confirms this view. 
AGE INCIDENCE

The age incidence of this condition is of special interest. It is almost unknown in the nursing baby, though $I$ have seen it in a baby on mixed feeding; is relatively rare in the first six months, and is only exceptionally encountered before the third or fourth month. It is much more common in the latter half of the first year; probably attains its maximum frequency and severity during the second year; becomes less common during the third year, and vanishes soon after this. The lesser incidence after the third year is probably due to the greater infrequency of bed wetting without which it would not be recognizable.

\section{TREATMENT}

The treatment of this condition naturally is directed to the lesion itself if it is present, and to the prophylaxis and treatment of the ammoniacal diaper.

If the meatus is ulcerated or crusted over to some extent, and there is no obstruction, the proper therapy would seem to consist in applying thickly some substance like petrolatum that would coat over the involved area so that urination may be less painful and so that there will be protection on contact with the diaper. When the meatus is acutely inflamed, the opening narrowed and covered with an obstructing scab, and urination is difficult and peculiarly painful because of the inflammatory condition, a wet boric acid dressing has always quickly relieved the urgent indications. Gauze wet with the solution is fluffed over and about the penis, this is covered with a thick layer of cotton extending beyond the gauze to keep it in place, and over this the diaper is pinned snugly. The gauze is kept wet with the solution and is changed after each urination. The relief from this procedure has been unfailing and almost instantaneous. Dispensing with the diaper at night often has a favorable effect in preventing new lesions and in allowing old ones to heal. Mechanical dilatation has never been necessary. Neither has catheterization, which would be strongly contraindicated unless absolutely unavoidable.

If the scab itself is causing obstruction, or if it can be removed without injury to the adjacent tissues, this should be done. This is facilitated by the previous application of petrolatum or a wet dressing.

The cautious application of a very weak solution of cocain to the ulcerated area in case the child will not urinate because of pain would seem rational and unobjectionable, though the remembrance of a former attempt to urinate might lessen its usefulness.

The prophylaxis of the ammoniacal diaper presupposes a knowledge of its pathogenesis. To my mind we do not possess this knowledge at the present time with complete clarity. 
The more inviting theory is that based on the work of Keller and others that in certain nutritional disturbances due to the ingestion of cow's milk fat beyond the infant's tolerance there is produced a relative acidosis of enteric origin which manifests itself in the urine in the excretion of a hypernormal amount of ammonium salts. This view has been formally championed by Southworth, ${ }^{2}$ who reported a number of cases presenting this clinical picture and the patients were relieved of this symptom when the fat was reduced to an adequate degree. He also reported a similar result from the administration of alkalies, favoring potassium, calcium and magnesium bases over those of sodium. The cases detailed by Southworth were nearly all in younger infants in whom there was a definite clinical picture of overfeeding with fat or with milk and the therapeutic results would seem to leave little doubt as to the nature of the primary condition that produced the ammoniacal diaper in these cases.

I am inclined to believe that this explanation may be accepted as one factor in the case of younger infants fed exclusively on the bottle. This might further explain the greater frequency of this condition in my own cases for it has been my practice in recent years to give relatively more milk and less carbohydrate in the bottle feedings than formerly. In fact, the condition has been so frequent in my own cases that $I$ have even assumed it to be within the range of normal and have used no measures to relieve it unless there was definite skin irritation. Even in these cases, however, where a dietetic relationship seems most evident $I$ have been struck by the frequency with which neither reduction of the fat by lessening the milk or by taking off the cream nor the use of alkalies leads to an appreciable therapeutic result.

It seems to me, however, quite impossible on this hypothesis alone to explain the occurrence of the ammoniacal diaper in a very large number of cases. It is, for example, a well known fact that the ammoniacal diaper occurs with greater regularity when dried milk is used than with almost any other food. In my own experience, the severer manifestations, such as vesication and ulceration, occur more frequently in older children who are on a liberal diet and are getting very little milk. One of the most severe and protracted cases $I$ have seen with extensive ulceration of the meatus, scrotum, and, in fact, of the whole diaper region, was in a child, aged $21 / 2$ years, that was on a general diet and getting only a pint of skimmed milk. In some cases the mothers have stated that these older children were getting practically no milk at all. Cutting down the milk or removing the cream, even to a marked degree, has in the case of older children been

2. Southworth, T. S.: The Ammoniacal Diaper and Its Correction, Arch. Pediat. 30:10 (Oct.) 1913. 
quite disappointing from a therapeutic standpoint. The use of alkalies has given the same impression.

\section{DISCUSSION}

It is interesting in this connection to note that the ammoniacal diaper occurs less frequently and less severely with cream mixtures than with simple whole milk mixtures, or even, as has been pointed out, with dried skimmed milk mixtures. If this observation is correct, then the fat alone cannot account for the condition. This is further borne out by the relative freedom from this symptom when albumin milk is given in spite of its high fat content. It will be recalled that Czerny and Keller's "milchnährschaden," which is apparently due to an excess of fat in the infant's food and in which there is a heightened urinary excretion of ammonium salt, is produced when whole milk is fed in excess of tolerance. Certainly, it does not occur as definitely with cream mixtures, in spite of the fact that fat is assumed to be the factor that causes it. It will be recalled further that Czerny and Keller state that the soap stool does not occur with cream mixtures and they offer the ingenuous explanation that this is due to the fact that it is difficult to get cream that is not "zersetzt," that is, unfavorably influenced by bacteria.

To me it seems more reasonable that while the symptom under discussion may be due to the fat, at least in that class of cases where there is clinical evidence of overfeeding with fat, that fat will cause it only in certain combinations, and only if certain other food elements are represented in certain relative ratios to the fat. Thus, in a milk mixture it occurs less frequently if the fat is relatively higher than the protein and the salts as compared with their normal relative representation in whole milk; and more frequently if the normal proportion is maintained, or even if the fat is relatively lower than the protein and the salts. The fact is not sufficiently emphasized that the different food elements cannot be considered as isolated factors but must always be considered in relation to the other food elements in the causation of clinical pictures.

While the fat within these limitations may account for an increased excretion of ammonium salts in a certain proportion of these cases, and may thus supply one factor in the pathogenesis of the ammoniacal diaper, I do not believe that it accounts for all or most of them. Even in those cases where the fat would seem most clearly the causal agent, it is impossible to exclude the protein, or even the salts as a factor. I have gained the impression that, in the production both of the clinical picture of "milchnährschaden," and of the ammoniacal diaper, it is not so much a matter of amount of fat as of the amount of 
milk even if it is partly skimmed. The protein and the salts, if this observation is correct, would command attention and especially, of course, the protein. This would explain many phenomena that cannot be accounted for on the assumption that the fat is the main factor. It would explain the frequency of the ammoniacal diaper when Dryco Milk is used in spite of its low fat content because as commonly used the amount of protein is relatively considerably higher than with ordinary fresh milk mixtures. Assuming that a milk from which two thirds of the fat has been removed is reduced to about one eighth or one ninth its volume in the process of desiccation, and that eight level tablespoonfuls of the dried product represent one ounce by weight, then one level tablespoonful would equal approximately one ounce of fresh milk, skimmed to a nearly equal extent. In giving two and one-half or even three tablespoonfuls of the dried milk to each pound of baby, as is commonly done, one would give the protein and salt equivalent of at least from $2 \frac{1}{2}$ to 3 ounces of milk to the pound of baby which would represent a much larger amount than is ever used in feeding fresh milk. This might also explain the greater frequency of the occurrence of the ammoniacal diaper in my own experience in more recent years during which $I$ have been feeding more milk, that is, more protein and less carbohydrate. On this basis, too, one might find a satisfactory explanation for those cases in older children that are on a nearly general, almost fat free, diet.

The failure of ammonuria to occur, except in connection with the wet diaper in situ, together with the peculiar behavior of the ammoniacal diaper would suggest a further nondietetic factor residing in the diaper itself. A hyperexcretion of ammonium salts cannot alone be assumed to account for the ammoniacal diaper. We have here not combined but free ammonia. The ammonium salts that would be present in this condition are fairly stable, and it is very doubtful whether the evaporation of the urine would be carried to a point where ammonia would be liberated to the extent found in these diapers. It is well known that certain alkalies break up ammonium salts and liberate free ammonia. On this basis Zahorsky, ${ }^{1}$ after failure to combat the condition by lessening the fat in the food and by the use of alkalies therapeutically, came to the conclusion that "the immediate cause of the ammoniacal diaper is the presence of an alkali in the diaper, or the bedding." This alkali he traced to "strong alkaline soap that had not been rinsed thoroughly from the diapers, or bedding, or to the presence of an alkaline stool, or to the possible presence of lime in the dried diaper in locations like St. Louis where the lime content of the water is high."

Zahorsky's explanation was distinctly appealing in that it alone, apparently, could account for the mysterious vagaries of the ammo- 
niacal diaper; the startling appearance and sudden disappearance without known change in food or in health; the invariable association with the wet diaper in situ only; the failure of dietetic and alkaline treatment in many cases; and the greater incidence and severity of the symptom in older children which he also noted. Unfortunately he contented himself with saying: "It is not necessary to give the details" and presented no evidence. That soap, lime, and an alkaline stool do not explain the condition in a great many cases can easily be demonstrated by excluding these factors experimentally.

Other agents, however, may produce the same result and the action of bacteria naturally suggests itself. Thus in a recent personal communication Zahorsky says: "The diaper or the bedding, infected by an enormous number of bacteria, not boiled daily, must also be considered." The thought would suggest itself further that bacteria might liberate ammonia, not directly or indirectly from the ammonium salts in the urine, but from the urea. It is well known, for example, that Micrococcus ureac, and probably also other organisms in the urine, act on urea with the liberation of ammonia. As suggested by Kendall in a personal communication, the large evaporating surface presented by the diaper as compared with the small surface in the test tube would naturally lead to the freeing of a comparatively larger amount of ammonia. These considerations would lead us back again to the clinical impression already recorded that the determining factor in those cases in which the dietetic factors are easily grasped is the amount of milk given even if skimmed; that is, of protein, rather than, say, the amount of fat. More milk carries with it more protein and an increased excretion of urea for bacteria to act upon.

The further question would naturally arise whether a hyperexcretion of ammonium salts, or of urea, due to an excess of either the fat or the protein in the diet, is a prerequisite to the production of the ammoniacal diaper; or whether something in the diaper itself is sufficient to elicit the condition in a normal urine. So far as I know, the answer to this question is not yet at hand. The fact that free ammonia occurs with great regularity with certain foods, and an excessive amount of fresh milk such as Dryco milk, would point to the conclusion that the diaper.alone is not sufficient to bring out this symptom tunless there is an abnormal urinary condition. The occurrence in older children on a general diet makes it hard to assume an abnormal urinary factor and would suggest that the diaper can cause it even if the urine is normal. The invariable association of this symptom with the diaper would again suggest the diaper as the important factor and especially in these cases where the symptom occurs erratically. Some further observations made by Zahorsky are interesting but inconclusive in this connection. He found that "the ammo- 
nia content of the urine was relatively higher in older children than in infants," and "while rather high in children presenting this symptom (ammoniacal diaper) not higher than in many who did not present it." He found further that "all but one of the patients so examined," that is, those having ammoniacal diapers, "showed the ammonia nitrogen higher in the morning after the night's rest." The fact that the ammoniacal diaper is rare in hospital cases as compared with those in private practice can be accounted for on either basis. In hospitals all diapers are thoroughly sterilized for obvious reasons, while in homes this is commonly omitted. On the other hand, it is also true that hospital babies, as a rule, can stand less milk than babies in private practice and so the dietetic factor is reduced to a minimum.

While our knowledge of the whole subject lacks precision and finality, nevertheless it gives us a definite line of treatment. The prophylaxis of the ammoniacal diaper and so of the ulcerated meatus, in accordance with our present state of knowledge, would consist then, in the avoidance of an excess of milk in the diet and a compensating use of the more tolerable carbohydrates, the dextrin-maltose preparations in younger infants, and these together with the starches in older infants. The treatment would consist in the reduction of the amount of milk; the increase, if permissible, of the carbohydrates; together with the use of such alkalies as milk of magnesia, lime water, or potassium salts. In selected cases malt soup best meets all of these indications. In older children on a general, nearly milk free diet, the dietetic treatment is still baffling in my own experience. The indications on the part of the diaper would be met by thorough rinsing and thorough boiling daily of all diapers and night clothes, possibly even the bedding.

The bearing of this lesion on the question of circumcision is perhaps evident.

\section{CONCLUSIONS}

1. An ulcerated meatus in the circumcised child only is a frequent symptom.

2. The "ammoniacal diaper" is the cause of this lesion.

3. The etiology of the "ammoniacal diaper" is still obscure but seems due to one or both of two factors: a dietic error that increases the ammonium or urea content of the urine, and the presence of an alkali or of certain bacteria in the diaper.

4. The treatment consists in correcting, if possible, the dietetic error and in thorough rinsing and boiling of the diapers, night clothes and bedding. 